\title{
Liter per Microgram per Kilogram per Day
}

National Cancer Institute

\section{Source}

National Cancer Institute. Liter per Microgram per Kilogram per Day. NCI Thesaurus.

Code C120811.

A unit of concentration equal to liter divided by microgram per kilogram per day. 